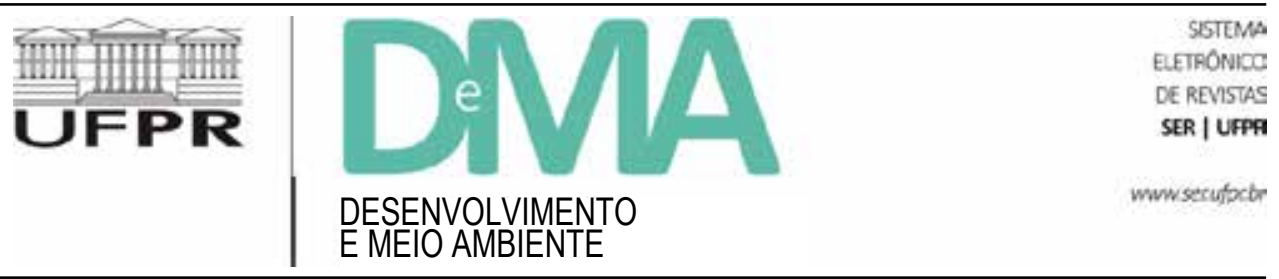

\title{
Duas secas climaticamente análogas no semiárido nordestino com impactos sociais distintos
}

\section{Two equivalent droughts with different social impacts in the Brazilian Semiarid Region}

\author{
Luis Cláudio MATTOS ${ }^{1 *}$, Peter MAY² \\ ${ }^{1}$ Universidade Federal Rural de Pernambuco (UFRPE), Recife, PE, Brasil. \\ ${ }^{2}$ Universidade Federal Rural do Rio de Janeiro (UFRRJ), Rio de Janeiro, RJ, Brasil. \\ *E-mail de contato: luis.mattos@ufrpe.br
}

Artigo recebido em 15 de maio de 2020, versão final aceita em 17 de setembro de 2020, publicado em 18 de dezembro de 2020.

RESUMO: O período de seca que a região semiárida viveu entre 2010 e 2016 transcorreu de maneira bem distinta do que em períodos passados. Ainda que a seca fosse a mais intensa de que se tem notícia, seus impactos foram significativamente menores, sem registros de calamidades sociais. Em parte, os seus impactos sociais foram atenuados em função de uma nova concepção de resposta para o enfrentamento da seca, construída gradativamente ao longo de pouco mais de duas décadas de transformações na região. Este artigo se concentra em três campos de análise: (i) as características do campesinato que compõe a base social da região; (ii) as relações agroecológicas dos sistemas difundidos nos últimos anos; e (iii) o processo de mobilização da sociedade civil e a construção de novas políticas para o semiárido. Inicialmente, realizou-se uma comparação entre os períodos de seca com base em dados climatológicos disponibilizados pelo Centro de Previsão de Tempo e Estudos Climáticos/INPE. A partir daí, o trabalho se valeu de metodologias participativas de diagnósticos dos sistemas e subsistemas agroecológicos que remetem à convivência com o semiárido, demonstrando a importância do seu papel na composição dos estoques e na conversão do capital natural em outros ativos para as famílias agricultoras. A multifuncionalidade e a pluriatividade do campesinato do semiárido cumpriram um papel decisivo na estabilidade dos sistemas e na segurança alimentar da família. $\mathrm{O}$ estudo registrou a trajetória de construção de políticas públicas em que as ideias relacionadas à convivência com o semiárido e o foco na agricultura familiar passaram a compor ações de enfrentamento da seca e promoção do desenvolvimento.

Palavras-chave: Semiárido; seca; políticas públicas; agricultura familiar. 
ABSTRACT: The drought period in the semi-arid region between 2010 and 2016 was quite different from those that occurred previously. Although this drought has already been considered the most intense ever seen, its social impacts were significantly less intense than they have been in the past, with no record of social disasters. Part of these different social impacts were related to a new way of mitigating the drought. This new response was gradually drawn up through two decades of political and social transformations in the region. This article is focused on three aspects of these transformations: (i) the characteristics of the local peasantry who make up the regional society; (ii) the agroecological relationship of the systems disseminated in recent years; and (iii) the process of civil society mobilization and building new policies for the semiarid region. Initially, a comparison was made between the intensity of droughts based on climate data from Center for Weather Forecasting and Climatic Studies/INPE. From this point on, the work was based on participatory appraisals of the agroecological systems and subsystems that refer to the increased ability to adapt to semi-arid region, demonstrating the importance of its role in the composition of stocks and in the conversion of natural capital into other assets for farming families. The multifunctionality and pluriactivity of the semiarid peasantry also played a crucial role in the stability of the systems and in the food security. The research recorded the path of the public policy development process in which the ideas related to living with the semi-arid conditions and the focus on family agriculture became actions in the combat of drought and promote development.

Keywords: Semiarid; drought; family farming; public policies.

\section{Introdução}

A relevância em abordar a seca no nordeste brasileiro contemporâneo não se dá em função da sua recorrência, mas pelo fato de, pela primeira vez na história, um longo período de sucessivos anos de seca não ter ocasionado calamidades sociais verificadas em outros tempos. Tal qual se previa em estudos antecedentes a este, a seca, como fenômeno climático, e suas consequências, como fenômenos sociais, correspondem a eventos relacionados, mas independentes. Assim sendo, não é a seca que move este estudo, mas as manifestações econômicas e sociais surgidas a partir dela.

O processo de modernização que marcou o desenvolvimento do país a partir da segunda metade do século XX necessitava que as calamidades peri- féricas fossem neutralizadas, não necessariamente enfrentadas. Evitar-se-ia com isso a convulsão social. Por outro lado, a manutenção no Nordeste semiárido de um estado permanente de pobreza e exclusão, tornado miséria e desespero em tempos de seca, servia de alicerce ao fornecimento de mão de obra barata para viabilizar a emergente produção industrial do país. Criaram-se os programas emergenciais para os tempos de seca e calamidade, alistando trabalhadores em "frentes de serviço", que acabavam por realimentar as estruturas sociais que davam sustentação ao regime político. Propagava-se, assim, a ideia da naturalização da seca e seus efeitos, fazendo crer à população que o problema era intrínseco à natureza da região semiárida e seu enfrentamento seria necessariamente periódico e paliativo.

\footnotetext{
1 "Frentes de serviço" ou "frentes de emergência" foram programas temporários criados excepcionalmente pelo Governo Federal em resposta à calamidade social que se estabelecia durante os períodos de seca. Por meio delas, o Governo alistava trabalhadores oriundos das áreas afetadas pela seca para serviços diversos, como melhoria das estradas, recuperação e manutenção de açudes e construção de passagens molhadas em estradas vicinais. $\mathrm{O}$ valor pago por esses serviços era bem abaixo do valor do salário mínimo e, não raro, complementado com distribuição de cestas básicas, ao invés de valores monetários (Olivi, 1983; Buriti \& Aguiar, 2008).
} 
Não se desconstroem socialmente fenômenos climáticos. Se em recorrências de secas não se verificam calamidades, é porque transformações na sociedade levaram a um novo estado de equilíbrio, alterando a realidade vivida pela população que lidava com as secas.

$\mathrm{O}$ período da investigação desse trabalho está compreendido basicamente entre os anos de 1993 e 2016, representando o tempo decorrente entre duas longas e abrangentes secas e em cujo período foram percebidas mudanças nas políticas públicas de preparação e resposta à crise por elas geradas.

\section{Introdução ao clima da região e as consequências da seca}

A região semiárida do Brasil está inscrita no interior do Nordeste Brasileiro e também no Norte de Minas Gerais (Figura 1), segundo a delimitação oficial do semiárido brasileiro (IBGE, 2018).

Além das baixas médias de precipitação total, possui uma grande irregularidade de chuvas no tempo e no espaço. Em certas localidades mais críticas, a média

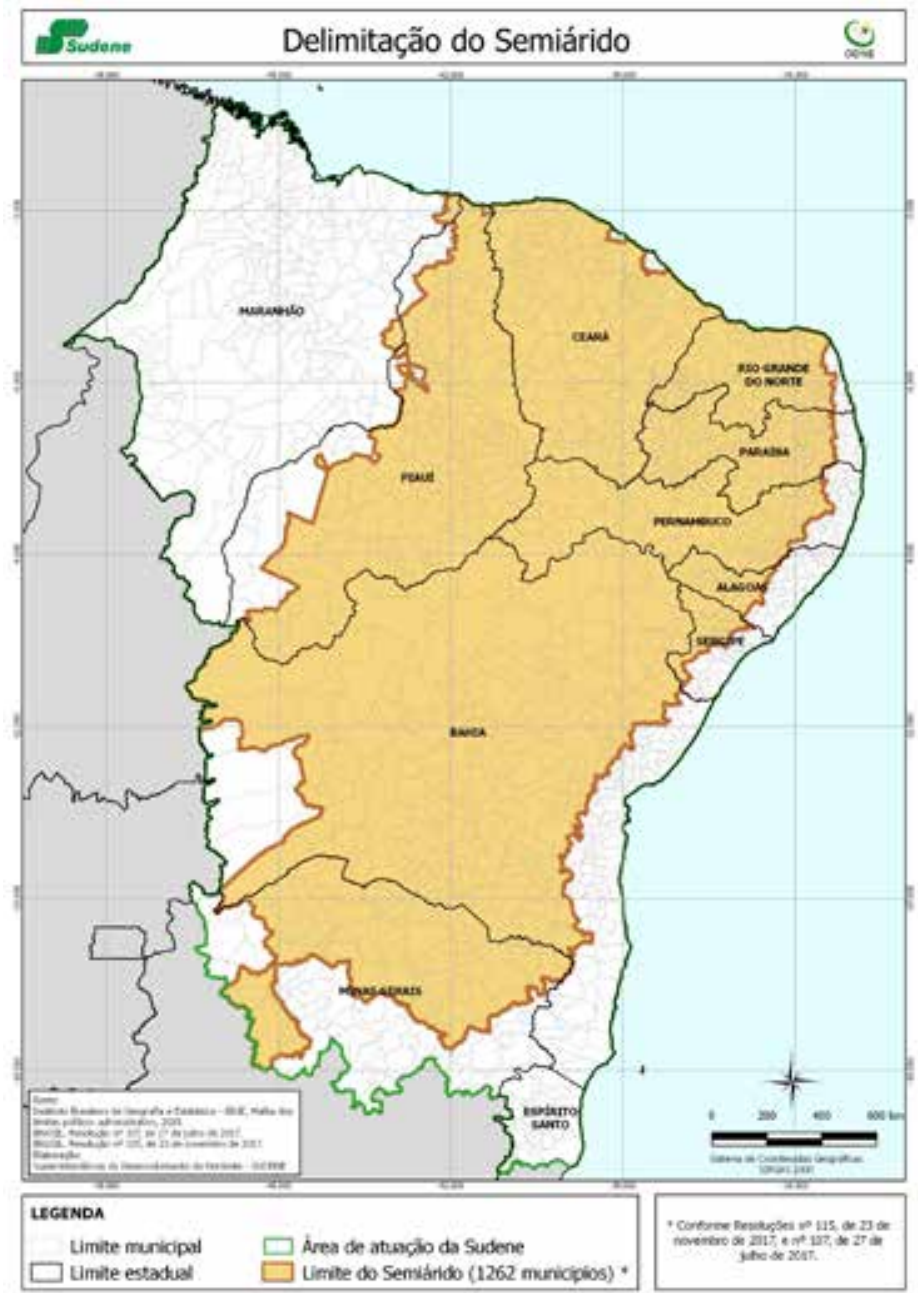

FIGURA 1 - Delimitação oficial do Semiárido brasileiro (IBGE, 2018). pode se situar em torno de $300 \mathrm{~mm} / \mathrm{ano}$. Entretanto, na maior parte da região, as precipitações médias situam-se entre 400 e $500 \mathrm{~mm} / \mathrm{ano}$ (CPTEC/INPE, 2016a). Esta grande variabilidade espacial e temporal de médias de precipitação indica que este não é um bom parâmetro para caracterizar a região (Nimer, 1989), tanto são irregulares as chuvas ao longo dos anos como dentro do mesmo período chuvoso.

Mesmo irregular, esta estação chuvosa principal se concentra em poucos meses, em geral três ou quatro. O restante do ano se caracteriza por uma estação seca prolongada, onde as chuvas não são só incertas, mas raras. As características das chuvas definem um saber popular que classifica os "anos" segundo os regimes de chuva dominante. Este saber local sobre diferentes perfis da estação chuvosa é um 
dos elementos da investigação proposta. Além disso, há anos em que as chuvas esperadas para a estação chuvosa situam-se muito abaixo da média. São seus efeitos e a percepção social deles que levam os habitantes a caracterizarem assim o fenômeno da seca.

Como consequência desta irregularidade, é comum verificar-se periódicos desabastecimentos de água nas vilas rurais, que, em épocas mais críticas, chegam a atingir também as cidades situadas na região. Além disso, é muito frequente a perda de colheita agrícola na estação chuvosa em sistemas sem irrigação. Este cenário apresenta um risco permanente para o abastecimento das famílias rurais, que dependem fundamentalmente do capital natural para a sobrevivência. Se nos anos regulares as produtividades já são baixas, nos períodos de seca as colheitas são incertas e perdas totais não são raras. A subnutrição, desnutrição ou mesmo a fome se tornaram aspectos que marcaram o regime alimentar da região por anos.

Neste sentido, ainda que a atividade econômica dominante na região seja a agricultura, paradoxalmente, não implica necessariamente ser a principal atividade de geração de renda.

\subsection{Relações entre ambiente e sociedade}

Na região semiárida, as questões ambientais estão na centralidade das relações econômicas e sociais, contribuindo para a organização do espaço agrário e dos hábitos familiares. A própria organização da sociedade, da cultura e da identidade se impõe a todos os seus moradores, em um processo de construção de identidade tão forte quanto os processos sociais coercitivos estudados por Durkheim (2007), mas que terão também aspectos relacionados à redução de riscos e à otimização. Há de fato uma naturalização do saber popular no enfrentamento dos períodos mais severos da seca, sendo o próprio termo bastante consensual em termos populares.

O conhecimento tradicional sobre as estratégias de enfrentamento das adversidades na região, principalmente nos períodos mais críticos, se torna um importante capital para a população local. A socialização e a circulação deste conhecimento acabam por ser fatores decisivos na convivência com o semiárido. É no âmbito das relações sociais, portanto, que este capital floresce e se reproduz. Este é mais um elemento relacionado à força dos laços fracos (Granovetter, 1973). Um dado importante a se considerar refere-se ao papel das mulheres no gerenciamento e na manutenção dos estoques garantidores da família. Do ponto de vista demográfico, as mulheres representam $50 \%$ da força de trabalho rural no semiárido. Na divisão social do trabalho no semiárido, as mulheres são frequentemente responsáveis pela gerência da água para uso doméstico e pela gestão da alimentação de toda a família. Neste sentido, desenvolvem uma noção precisa dos estoques relacionados à segurança alimentar, além de participarem ativamente na produção de alimentos de mesa, cultivados com frequência em sistemas sofisticados de quintais. Entretanto, há uma confusão no meio rural daquilo que é considerado trabalho doméstico e trabalho produtivo, já que todas estas tarefas a elas incumbidas são consideradas em grande parte trabalho doméstico.

$\mathrm{Na}$ agricultura familiar, as mulheres desempenham um papel extremamente importante. Além das responsabilidades sobre o chamado trabalho reprodutivo, elas também estão a cargo de importantes sistemas produtivos. As mulheres também 
atuam fortemente na gestão dos recursos naturais e na conservação da biodiversidade, selecionando e preservando variedades de sementes e raças de pequenos animais mais apropriadas para a convivência com o semiárido. Assim, elas cumprem um papel fundamental na segurança alimentar, nutricional e hídrica. Quando os reservatórios ou fontes de água se tornam distantes, recai sobre as mulheres a pesada tarefa das várias viagens ao dia para suprir a necessidade da água, uma dura jornada com latas de água na cabeça e que aumenta com o aprofundamento da seca (Ferreira, 2008). Segundo a autora, as mulheres da agricultura familiar chegam a trabalhar 58 horas em média por semana contra 41 horas dos homens, com 23 horas dedicadas à chamada "reprodução social" contra apenas nove dos homens. Por isso, permanecem com frequência invisíveis até delas mesmas, que tendem a deduzir do que chamam de trabalho produtivo as atividades domésticas e para autoconsumo, que englobam o trabalho nos "quintais" (Di Sabbato et al., 2009).

\subsection{Os estigmas da região semiárida $-a$ fome e o atraso}

Josué de Castro foi um dos pioneiros na descrição da fome como fenômeno social, que pode ser considerado circunstancial quando se restringe a pequenas parcelas da população. No entanto, toma outra dimensão quando a fome ou a desnutrição atinge, por exemplo, a metade da população. Além disso, o autor distinguiu dois tipos de fome: a fome endêmica, quando possuir caráter permanente, e epidêmica, quando seu caráter é transitório ou conjuntural, ocasionado por um momento de crise ou catástrofe (Castro, 1984). Portanto, a face mais evidente do Nordeste Semiárido, a calamidade social em tempos de seca, que era determinante no seu estereótipo nacional, tornara também a sua fome peculiar e distintiva do restante do país. A vulnerabilidade da produção agrícola na região semiárida se intensifica durante a seca. Para os agricultores e agricultoras, trabalhadores e trabalhadoras sem-terra, estes períodos de seca prolongada colocam duramente à prova as capacidades das famílias agricultoras em resistir e se adaptar a um contínuo processo de exaustão de estoques.

$\mathrm{O}$ fenômeno da seca não tem um início e um fim claramente definidos. Só se tem a noção de que o ano é de seca quando ela já promoveu estragos. Ao longo destes anos, os agricultores e agricultoras tendem a esgotar inteiramente seus estoques de sementes e de água, na tentativa de plantar uma, duas ou três vezes, a fim de produzir. Este ciclo efetivamente destrói a sua capacidade para plantar quando a estação chuvosa se reestabelece em um ano vindouro. Quando as próximas chuvas chegam, as famílias ficam sem os meios para começar de novo. Quanto mais estruturada for a propriedade agrícola, melhores as condições para suplantar os períodos secos. Mas, para que sejam eficazes, os investimentos precisam ser realizados ao longo de anos com chuvas regulares.

\section{Secas de longa duração e sua analogia}

Registros documentais das características da região semiárida são antigos e ainda assim a caracterização da seca como fenômeno climatológico tem sofrido evolução com os avanços tecnológicos. Em termos práticos, reconhece-se a seca muito mais pelos seus impactos visíveis, e socialmente percebidos, do que pela caracterização climatológica do período em questão. 
O Quadro 1 apresenta períodos historicamente reconhecidos de ocorrências de secas no Nordeste. Ainda que suas identificações e caracterizações tenham sido realizadas sob critérios díspares e potenciais de comparação duvidosos, servem como parâmetro para inferir sobre suas longevidades, oferecendo um guia para iniciar-se uma investigação. Os períodos mais recentes ainda se encontram

QUADRO 1 - Histórico de secas conhecidas no Nordeste brasileiro (Villa, 2000).

\section{Registros de Seca do Nordeste}

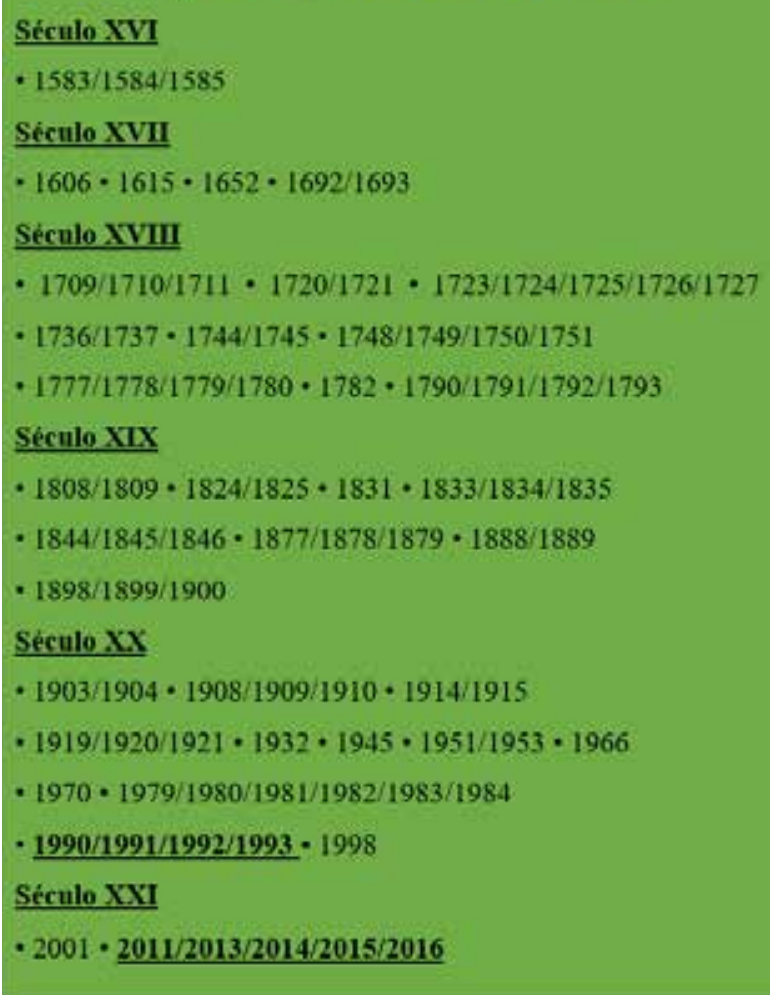

presentes nos imaginários populares e alimentam debates nas comunidades. Os períodos grifados de 1990 a 1993 e 2010 a 2016 são de longa duração e se tornam, assim, análogos para efeito desse estudo. Para afirmar tal analogia, recorreu-se aos Índices de Precipitação Padronizados (do acrônimo em inglês SPI - Standard Precipitation Index ${ }^{2}$ ), que permitem o monitoramento de condições associadas a secas e excesso de chuva (CPTEC/INPE, 2016b). Nesta comparação, tomaram-se os dados referentes apenas aos meses onde se concentra a quadra chuvosa na maior parte da região semiárida do Nordeste, que corresponde aos primeiros seis meses do ano, ou seja, SPI-06-Junho.

Os dados de chuva demonstram que as chuvas do mês de dezembro de 1989 foram bastante acima da média esperada para o período (Figura 2). A partir daí, se iniciou um período de estiagem que se estendeu por quatro anos, entre 1990 e 1993 (Figura 3 ). A percepção dos anos secos pelas famílias rurais indica o estado de emergência que se instaurou ao longo de quatro anos, quando os estoques de água, forragem e alimentos foram sendo gradativamente reduzidos (Mattos \& Trier, 1994).

Anos seguidos sem produção agrícola, sem recomposição da vegetação nativa e debilitados estoques de água, mais uma vez, instauraram um processo de calamidade social generalizada em toda a região semiárida. Além disso, ainda eram frágeis as políticas de proteção social para a população. As intensas chuvas de 1994 marcaram o seu fim.

A Seca 1990-93 não foi fundamentalmente diferente, do ponto de vista climático, dos episó-

\footnotetext{
2 O SPI é baseado somente no produto de precipitação mensal e padronizado segundo a precipitação esperada para o período (McKee et al., 1993). Desta forma, o uso do SPI permite comparar a mesma região em anos diferentes, detectando-se tanto as condições úmidas como as secas. Os números associados ao SPI referem-se aos meses anteriores ao mês de referência. Ex: o SPI-2-Junho considera dados de maio e junho.
} 


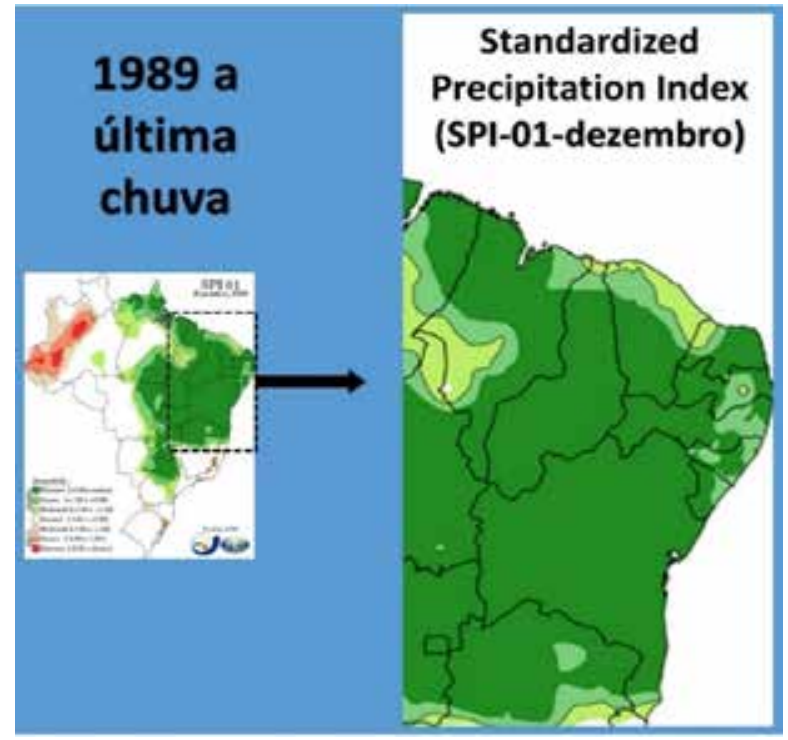

FIGURA 2 - SPI 1 em dezembro de 1989, indicando a precipitação que antecedeu um longo período de secas entre 1990 e 1993.

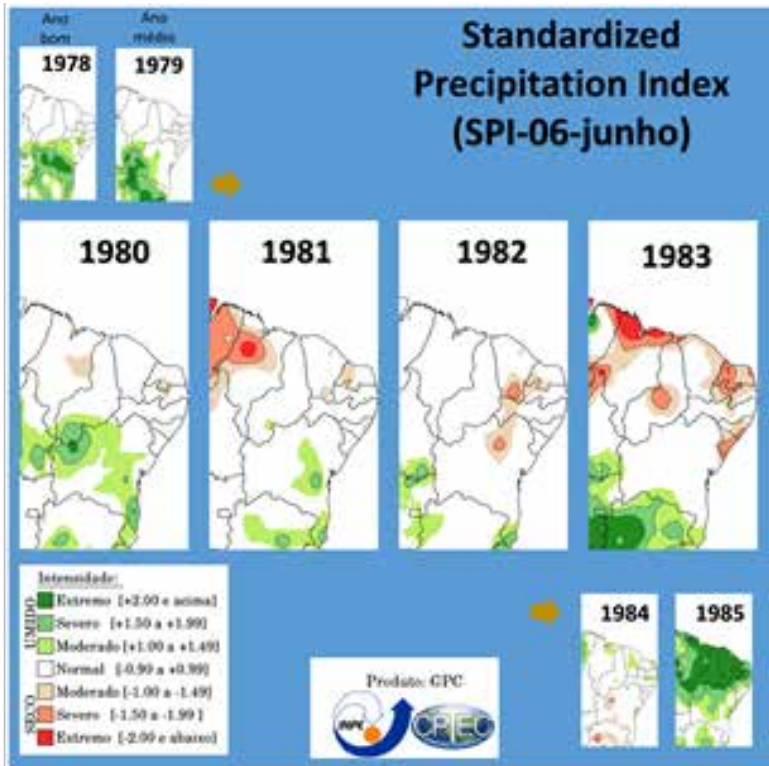

FIGURA 4 - Seca de 1980-1983 através dos SPI-6-jun em cada um dos anos considerados secos.

dios de seca prolongada que a antecederam, tendo impactos igualmente semelhantes. O período mais severo havia ocorrido 10 anos antes, entre 1980 e 1983, cujos dados de chuva encontram-se apresentados na Figura 4.

Por sua vez, a partir de 2012 a 2015, as chuvas foram extremamente fracas e muito abaixo da média em praticamente toda a região (Figura 5). A sucessão de estiagens ao longo dos períodos mencionados corresponde a anos descritos como críticos pelas comunidades rurais nas regiões investigadas. As chuvas de janeiro de 2016 levaram muitos a acreditarem que representavam o fim deste ciclo de estiagens. Analisando-se o SPI-01 de janeiro de 2016, observa-se que as chuvas se tornaram circunscritas apenas a este mês (Figura 6). Ao longo dos meses subsequentes, as chuvas voltaram a estar muito abaixo da média esperada, totalizando défi- 


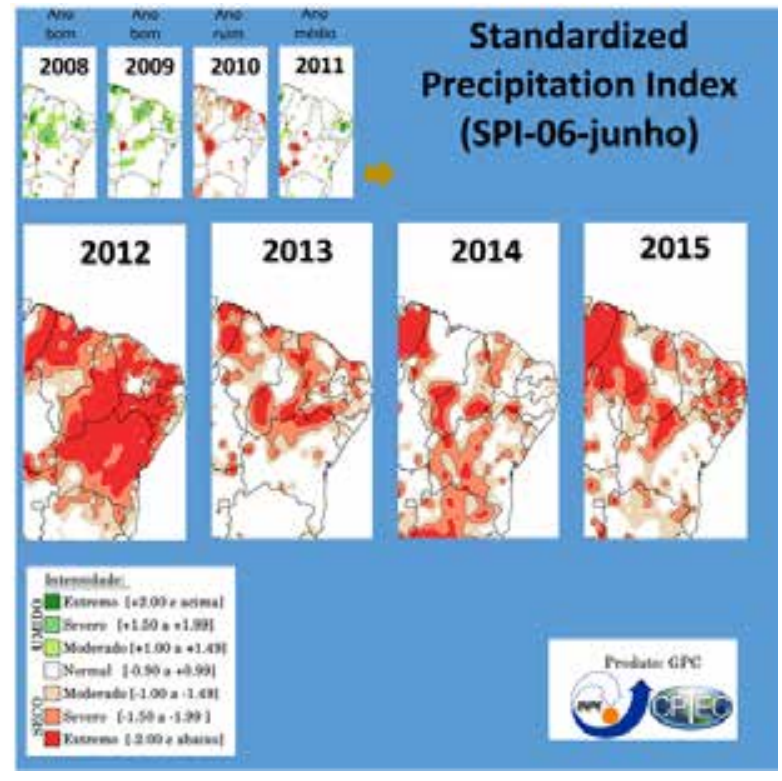

FIGURA 5 - Seca de 2012 em diante através dos SPI-6-jun em cada um dos anos considerados secos.

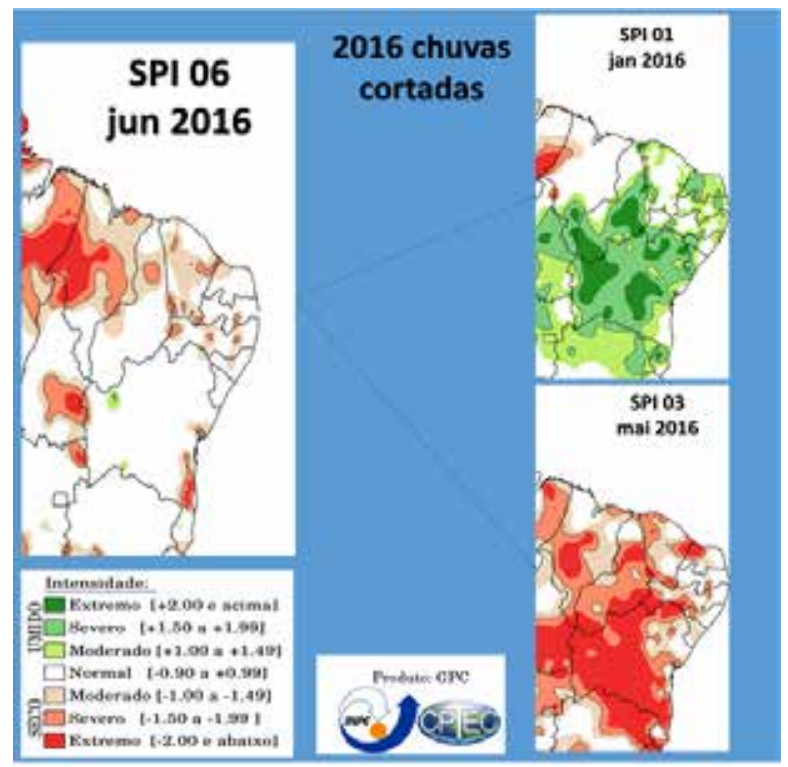

FIGURA 6 - Dados de precipitação do ano de 2016 desagregados em SPI-01-jan e SPI-03-mai indicando ser este um ano de seca verde e chuvas cortadas. cits consideráveis, registradas no SPI-03 de maio de 2016. Ao final da quadra chuvosa, 2016 acabou por se tornar um ano globalmente ruim (SP1-06 de junho), cujas chuvas se enquadram na descrição popular como "chuvas cortadas".

Apesar de ser um ano globalmente ruim, as chuvas concentradas atenuaram a seca ao garantir alguma água armazenada em reservatórios, mesmo que não tenham sido suficientes para garantir boas colheitas ou formar pasto para os animais.

Além disso, analisando-se os dados climáticos acima, percebe-se claramente que a seca de 201216 foi mais intensa e abrangente do que as suas antecessoras, e já é considerada a mais intensa e abrangente de que se tem notícia, superando até mesmo a seca de 1980-83.

\section{Diferenças nos impactos das secas de 1990-93 e 2012-16}

Para compreender o período 1990-93, é preciso mencionar o seu análogo anterior, ocorrido 10 anos antes. Ao longo de 1980-83, a resposta emergencial do Governo ao problema já era fortemente amparada na constituição de frentes de emergência, política instituída a partir de 1979 (Buriti \& Aguiar, 2008), e na tradicional distribuição de alimentos (Olivi, 1983).

Com a crise da cotonicultura nos anos 1980 , e por consequência do sistema produtivo gado-algodão-policultura alimentar, milhares de pequenos estabelecimentos sofreram rápida descapitalização, agravando os efeitos da seca. Com esta crise, desaparecem importantes oportunidades de ocupação sazonal da mão de obra. Além disso, a economia local foi também atingida pela crise macroeconômi- 
ca dos anos 1980 (endividamento externo, inflação, pacotes econômicos) e pela estagnação dos anos 1980 e 1990 (Buainain \& Garcia, 2013).

Como resultado, verificou-se uma vez mais a intensificação do processo migratório sazonal, preferencialmente de homens, "chefes" de família pela tradição do patriarcado. Com isso, eleva-se o número de estabelecimentos familiares rurais chefiados por mulheres. O momento de abertura política no qual a seca de 1990-1993 ocorreu permitiu que aquela geração conhecida como "Viúvas da Seca" se tornasse internacionalmente conhecida, chamando a atenção de organizações de ajuda humanitária dos países centrais. O Brasil passou a compor a lista de países prioritários para recebimento de alimentos pelo Programa Mundial de Alimentação (PMA) das Nações Unidas.

O período de secas compreendido entre 2010-16 se iniciou sem que fosse completamente percebido. Isto se explica em parte pela situação

TABELA 1 - Impactos da seca sobre as colheitas dos sistemas de roçado em Tamboril, Campo Alegre de Lourdes/BA.

\begin{tabular}{|c|c|c|}
\hline Ano & Avaliação dos agricultores & Observações dos agricultores colhidas em campo (Mattos, 2017) \\
\hline 2016 & Ano ruim & $\begin{array}{l}\text { - Chuvas irregulares } \\
\text { - Juntou um pouco de água } \\
\text { - Mas não teve colheita } \\
\text { - Roças de baixio tiveram melhor resultado } \\
\text { - Teve muita gente que plantou e não colheu } \\
\text { - Expectativa de 2016: PIOR }\end{array}$ \\
\hline 2015 & Ano ruim & $\begin{array}{l}\text { - Houve alguma colheita } \\
\text { - Colheram feijão verde } \\
\text { - Usaram Nim para combater pulgão } \\
\end{array}$ \\
\hline 2014 & $\begin{array}{c}\text { Ano ruim } \\
\text { (Pior que 2015) }\end{array}$ & $\begin{array}{l}\text { - Nem nasceu e não colheu nada } \\
\text { - Perderam muitos animais ruminantes, sobretudo bovinos e ovelhas } \\
\text { - Faltou alimento para animais: pasto -> restos de roçado -> ração } \\
\text { - Moveram os animais para não vender }\end{array}$ \\
\hline 2013 & Ano médio & $\begin{array}{l}- \text { Teve alguma colheita } \\
\cdot 4 \text { sacos de feijão } \\
\cdot 3 \text { sacos de milho } \\
\end{array}$ \\
\hline 2012 & Ano médio & $\begin{array}{l}\text { - Faltou para a colheita } \\
\text { - Colheita irregular } \\
\text { - Quintal foi bom } \\
\text { - Teve água no riacho } \\
\end{array}$ \\
\hline 2011 & Ano razoável & $\begin{array}{l}\text { - Colheram } 10 \text { sacos } \\
\text { - Esta colheita garantiu feijão até } 2013 \\
\text { - Guardou dele para plantar (ninguém mexe!!) }\end{array}$ \\
\hline $\begin{array}{l}2010 \\
2009\end{array}$ & $\begin{array}{l}\text { Ano médio } \\
\text { Ano bom }\end{array}$ & $\begin{array}{l}\text { - Havia expectativa pelo fim da seca em breve } \\
\text { - Colheita de } 9 \text { a } 10 \text { sacos }\end{array}$ \\
\hline 2008 & Ano muito bom & $\begin{array}{l}\text { - "Ano bom mesmo foi o de } 2008 ! ! ! " \\
\text { - Deu para pescar no riacho } \\
\text { - Teve mais de } 20 \text { sacos de colheita } \\
\text { - Teve muita água }\end{array}$ \\
\hline
\end{tabular}


mais favorável em que ele encontrou as famílias atingidas. A não ser pela quebra de safra já no primeiro ano, não se falava da seca até os idos de 2012. Este "passar despercebido" já era o sintoma de que os seus impactos seriam distintos, já que as secas anteriores já se faziam sentir desde os primeiros anos de estiagem.

Era de se esperar que durante o período de 2012-16, que também contou com precipitações nulas ou muito abaixo da média, os estoques de forragem e água se exaurissem, atingindo níveis insuficientes para a manutenção dos rebanhos ou mesmo para o abastecimento das famílias no campo, ocasionando a calamidade social tradicionalmente observada em secas de longa duração. De fato, as observações de campo junto aos/às agricultores e agricultoras entrevistados/as indica que houve uma queda brutal nas safras dos anos compreendidos por esta seca.

Uma combinação de políticas de ação permanente - sociais, ambientais, infraestrutura, etc. - fizeram a seca de 2012-16 parecer muito distinta das suas predecessoras. Registros oficiais e o noticiário das imprensas local e nacional não indicaram ocorrências de saque e desespero pela população afetada, não se configurando a calamidade social verificada em anos anteriores. Este fato chamou a atenção de algumas autoridades públicas, bem como de gestores de programas sociais na região.

Algumas das razões que levaram a estes distintos resultados foram estudadas e relacionadas entre si. Diante da quebra de safra generalizada relatada pelos/as entrevistados/as, é possível afirmar que os investimentos e políticas públicas tornaram as famílias menos dependentes da agricultura.

\section{Sobre a demografia na região semiárida}

Uma questão que pode influenciar o impacto das diferentes secas é a concentração de pessoas na área atingida. O êxodo rural sempre foi uma caraterística marcante da região semiárida, cuja emigração predomina sobre a imigração. Mas, ao contrário do que se poderia inferir sobre a população sertaneja, não há uma redução perceptível da população ao ponto de ser esta a causa da redução da calamidade social (Leite \& Souza, 2012). Ao contrário, as altas taxas de natalidade nas famílias sertanejas foram suficientes para superar as taxas de mortalidade e emigração e a população seguiu crescendo.

Os dados da população nordestina, colhidos em recenseamentos desde o século XIX, indicam um forte e contínuo crescimento populacional, que não fora abalado nem nos períodos de seca no Nordeste, nem durante a expansão industrial do Brasil no período pós-guerra (Figura 7). A curva de crescimento apresenta, no entanto, uma mudança de tendência, que sai da expansão exponencial para um crescimento linear, com ligeira tendência a uma estabilidade no ano 2010.

Os dados da evolução populacional não são desagregados para a região semiárida. Mesmo assim, ao retratar o Nordeste como um todo, eles permitem inferir sobre a tendência para a região semiárida pela comparação com dados desagregados para os anos mais recentes. A Tabela 2 mostra que entre 2000 e 2010 a população das microrregiões do Nordeste que perfazem o semiárido brasileiro teve aumento de mais de $8 \%$.

De fato, durante o período delimitado por esta pesquisa, a população da região crescera, mesmo que abaixo da média de crescimento no restante do país (Medeiros et al., 2012; Leite \& Souza, 2012). 


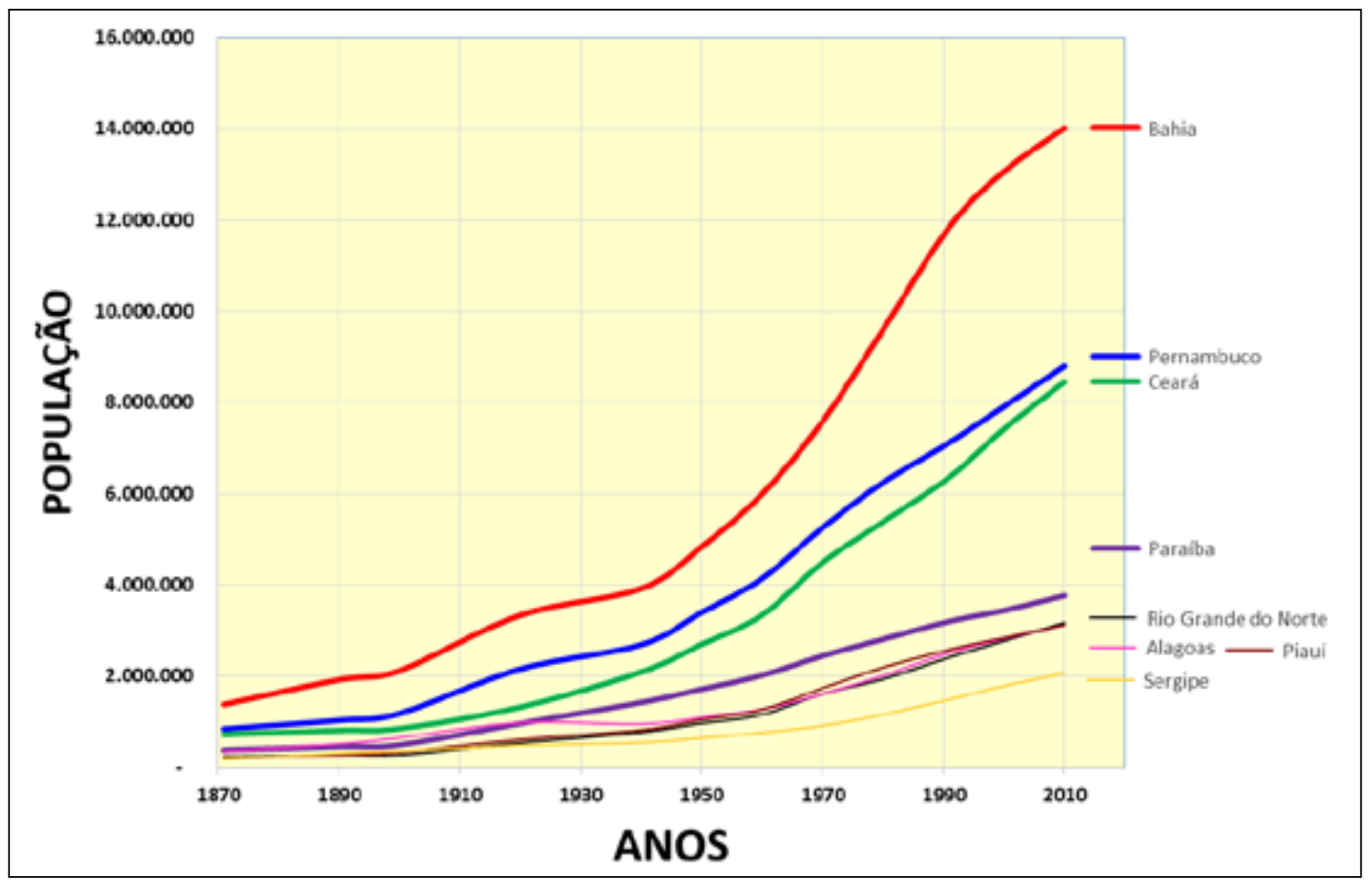

FIGURA 7 - Gráfico da evolução da população dos Estados do Nordeste segundo o IBGE (Leite \& Souza, 2012).

A seca e a calamidade sempre foram fatores adicionais de estímulo ao êxodo rural, quando se verifica a migração ema massa da população para regiões economicamente mais desenvolvidas em busca de oportunidades. No entanto, mesmo assim, a população seguiu aumentando na região, ao menos até os últimos anos do século XX.

Além disso, salvo em alguns casos excepcionais e particulares, praticamente não há variação na densidade demográfica dos municípios que compõem a região semiárida. Uma das exceções é para a região do polo agroindustrial situada na área de influência dos municípios de Petrolina, em Pernambuco, e Juazeiro, na Bahia (Figura 8). Isso indica a tendência a uma estabilidade da população na região semiárida, mostrando que o fluxo migra- tório na região foi reduzido ou invertido, dado que há também indícios da redução no tamanho médio da família.

Outra questão relevante para o trabalho se refere ao envelhecimento percentual da população (Figura 9). Ele se associa tanto ao aumento da expectativa de vida da população quanto à redução da taxa de natalidade. Quando se associa este fenômeno às políticas públicas de seguridade social, acaba por se tornar crucial para se compreender a diminuição da calamidade social causada pela seca. Por sua vez, o maior acesso a políticas públicas está na razão direta do acesso à informação, sendo a leitura um caminho. O que se viu nos últimos anos foi um aumento expressivo das taxas de alfabetização 
(Figura 10), que é indicador também do nível de que se quer é simplesmente testar se os diferentes escolaridade da população. impactos de secas prolongadas têm relação com a

Não se trata aqui de investigar os componentes flutuação negativa da demografia regional. específicos do balanço demográfico na região. $\mathrm{O}$

TABELA 2 - Evolução da população nos territórios do semiárido nordestino.

\begin{tabular}{|c|c|c|c|c|}
\hline \multirow{2}{*}{ Unidade da Federação } & \multirow{2}{*}{ Mesorregião } & \multicolumn{3}{|c|}{ POPULAÇÃo } \\
\hline & & 2000 & 2010 & Var.\% \\
\hline Piauí & Sudeste Piauiense & 479.731 & 519.395 & 8,27 \\
\hline \multirow{6}{*}{ Ceará } & Centro-Sul Cearense & 357.360 & 376.239 & 5,28 \\
\hline & Jaguaribe & 484.830 & 528.274 & 8,96 \\
\hline & Noroeste Cearense & 1.178 .307 & 1.326 .771 & 12,60 \\
\hline & Norte Cearense & 876.403 & 1.006 .582 & 14,85 \\
\hline & Sertões Cearenses & 814.125 & 869.778 & 6,84 \\
\hline & Sul Cearense & 789.262 & 876.600 & 11,07 \\
\hline \multirow{3}{*}{ Rio Grande do Norte } & Agreste Potiguar & 388.144 & 426.757 & 9,95 \\
\hline & Central Potiguar & 360.547 & 381.846 & 5,91 \\
\hline & Oeste Potiguar & 742.054 & 826.707 & 11,41 \\
\hline \multirow{3}{*}{ Paraíba } & Agreste Paraibano & 1.151 .075 & 1.213 .279 & 5,40 \\
\hline & Borborema & 277.116 & 298.263 & 7,63 \\
\hline & Sertão Paraibano & 819.040 & 863.178 & 5,39 \\
\hline \multirow{3}{*}{ Pernambuco } & Agreste Pernambucano & 1.993 .868 & 2.217 .600 & 11,22 \\
\hline & São Francisco Pernambucano & 465.672 & 578.203 & 24,17 \\
\hline & Sertão Pernambucano & 911.914 & 996.830 & 9,31 \\
\hline \multirow{2}{*}{ Alagoas } & Agreste Alagoano & 580.543 & 623.302 & 7,37 \\
\hline & Sertão Alagoano & 411.272 & 432.667 & 5,20 \\
\hline \multirow{2}{*}{ Sergipe } & Agreste Sergipano & 404.548 & 446.207 & 10,30 \\
\hline & Sertão Sergipano & 196.396 & 224.691 & 14,41 \\
\hline \multirow{4}{*}{ Bahia } & Centro-Norte Baiano & 2.080 .336 & 2.226 .300 & 7,02 \\
\hline & Centro-Sul Baiano & 2.472 .375 & 2.478 .787 & 0,26 \\
\hline & Vale São-Franciscano da Bahia & 877.034 & 964.405 & 9,96 \\
\hline & TOTAL & 19.113.952 & 20.702 .661 & 8,31 \\
\hline
\end{tabular}

FONTE: IBGE. Censo 2010, Resultados do Universo agregado por setores, e Censo 2000, Resultados do Universo agregado por setores (Leite \& Souza, 2012). 


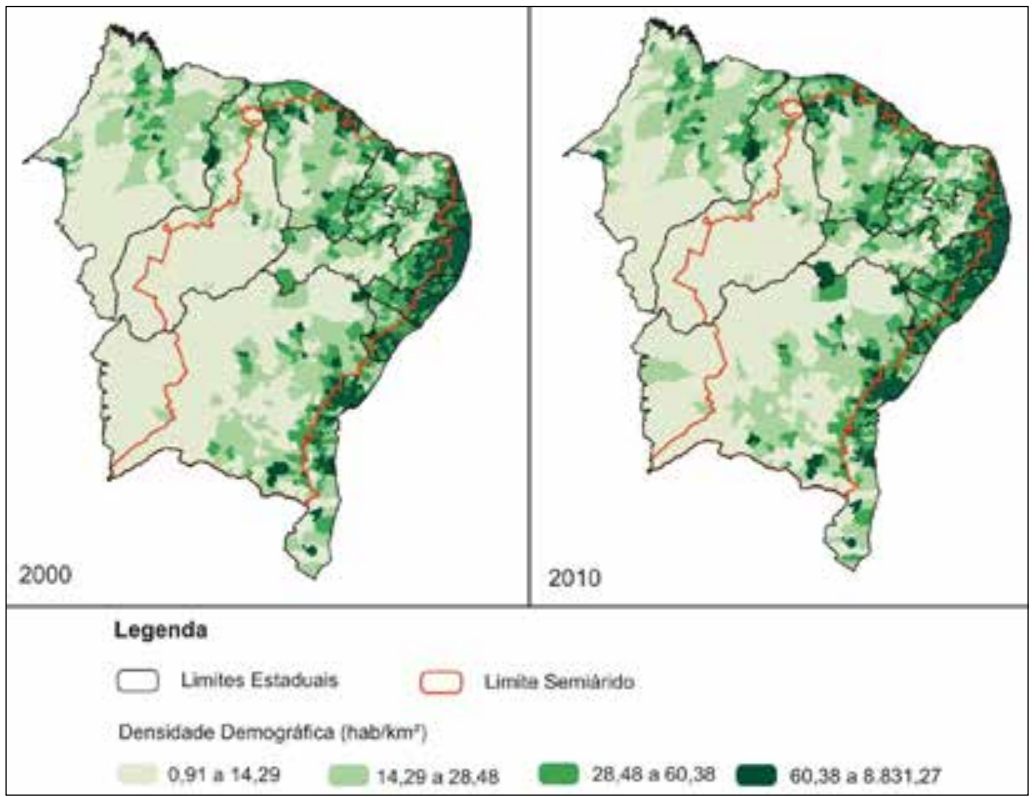

FIGURA 8 - Densidade Demográfica dos Municípios do Nordeste - 2000-2010 (Leite \& Souza, 2012).

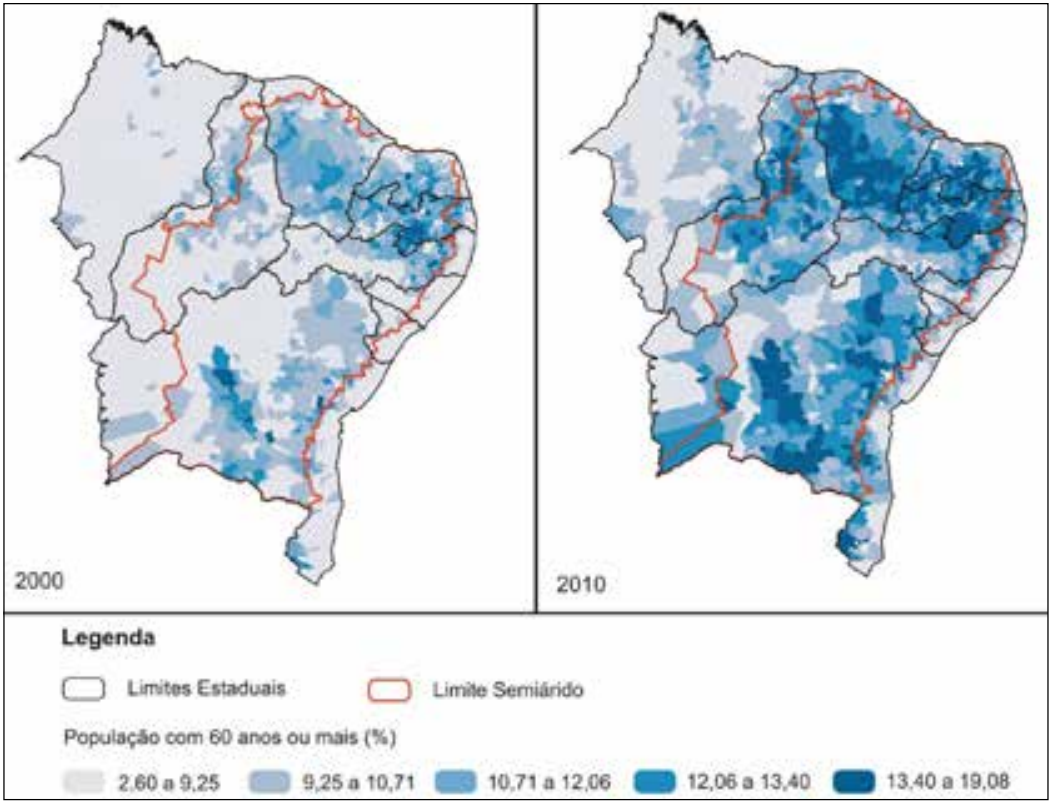

FIGURA 9 - Proporção de pessoas com 60 anos ou mais de idade, por municípios - Nordeste, com base nos Censos 2000 e 2010 (Leite \& Souza, 2012). 


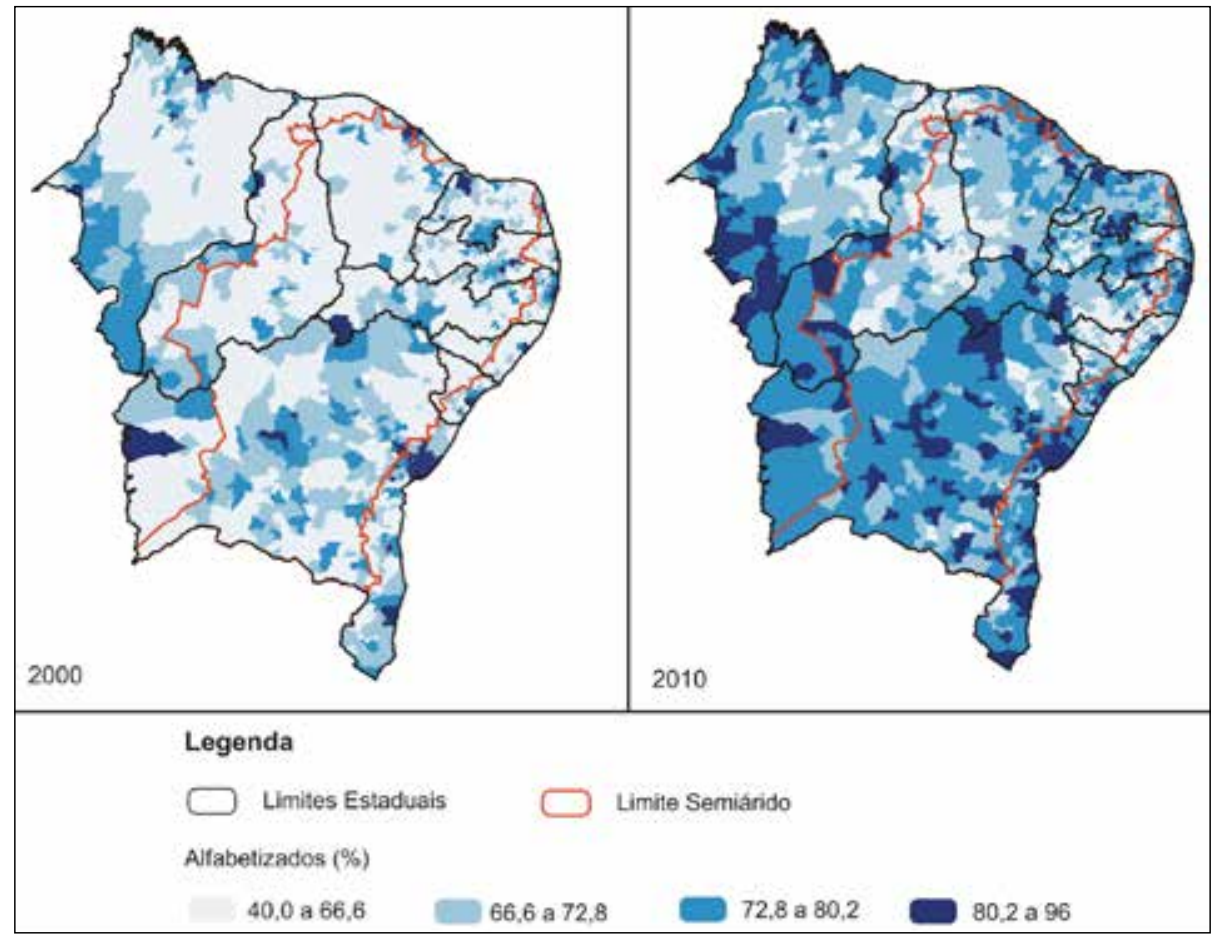

FIGURA 10 - Municípios do Nordeste, segundo a Proporção de Alfabetizados na População (Leite \& Souza, 2012).

\section{Hipóteses descartadas}

Os dados apresentados anteriormente indicam que os períodos de seca analisados 1990-93 e 201216 foram, não só climaticamente análogos, como as variações percebidas em termos de magnitude, intensidade e longevidade pesaram ainda mais para o segundo. Portanto, não se pode creditar a redução dos impactos sociais da seca, às diferenças de magnitude, já que entre 2012 e 2016 não se registraram saques e situações de calamidades vividas no passado pela população.

Outra questão refere-se à possibilidade de que o êxodo rural, que sempre foi uma caraterística da região semiárida, pudesse influenciar a redução do impacto social pela diminuição da população do semiárido. A emigração da população, e uma eventual redução da densidade demográfica, tenderia a atenuar os impactos da seca pela redução dos efeitos sociais visíveis.

É verdade que a região é historicamente exportadora de mão de obra. Mas, nos últimos anos, a redução da demanda no mercado de trabalho brasileiro por mão de obra desqualificada oriunda da região semiárida, entre outros fatores, reverteu esta tendência. Do ponto de vista demográfico, os dados do IBGE, apresentados acima, demonstram que não houve nesse período um esvaziamento demográfico 
significativo na região. Ao contrário, a população na região seguiu crescendo. Não residem aí as causas da redução dos impactos sociais das secas e, portanto, essa hipótese foi completamente refugada.

\section{Fatores de mudança}

\subsection{A convivência com o semiárido e a descentralização da oferta de água}

Se os diferentes impactos não podem ser explicados pelas características da própria seca nem pelas mudanças demográficas da região, as diferenças podem indicar que, no transcorrer de 20 anos, transformações nos paradigmas dominantes em ações de enfrentamento da seca permitiram melhores resultados na mitigação dos seus efeitos para além do paradigma da solução hidráulica ${ }^{3}$ (Campello Netto, 1994.

Esse modelo, considerado paliativo, tratava apenas os períodos de crise durante a seca. Estudos de modelização climática demonstraram a influência da temperatura na superfície dos oceanos e as anomalias de precipitação na região Nordeste, tornando o fenômeno cada vez mais previsível (Aragão, 1986; Harzallah et al., 1996), demonstrando que as graves crises eram devidas mais a questões sociais do que climáticas, o que permitiu pouco a pouco se construir bases para se "conviver com a seca e com o semiárido" ao invés de "combater a seca".
A seca continua sendo recorrente e, sendo cada vez mais previsível e suas consequências por demais conhecidas, passou-se a uma nova fase na reação da sociedade. Cresceu a percepção na sociedade sobre a manipulação da seca como impulsionadora do capital político para dominação. Neste sentido, a mudança só poderia surgir por meio da mobilização política para busca de respostas. Um sem-número de alternativas começou a ser testado para permitir a convivência com o semiárido, com a descentralização da oferta de água, a captação e o armazenamento local, a constituição de estoques de água, sementes e forragem, e o uso racional dos recursos naturais.

Ainda que as tecnologias adaptadas tenham sido implementadas desde os anos 1990, sua eficiência na convivência com o semiárido jamais havia sido testada para adaptação dos sistemas produtivos e para a melhoria das condições domiciliares em estiagens prolongadas, o que aconteceu a partir dos anos 2010.

As tecnologias hoje conhecidas foram desenvolvidas e adaptadas após este período e não tinham sido ainda testadas em períodos prolongados de seca, como o observado entre 2012-16. Só agora é possível saber em condições reais qual foi a contribuição destas tecnologias em atenuar a situação de seca ou permitir a adaptação da vida cotidiana a ela.

A busca por alternativas tecnológicas que garantissem mais adaptação ao meio e melhores condições de convivência com o semiárido seguiu os princípios da agroecologia. Ainda que não estivesse claro desde sempre que convivência com semiárido

\footnotetext{
3 A expressão "solução hidráulica" vem sendo utilizada desde os anos 1950. Trata-se de um modelo de ação pública pelo viés exclusivo de obras de engenharia e financeirização da agricultura, com manutenção ou aprofundamento da estrutura agrária e social de dominação. As obras hídricas de grande porte cumprem, contudo, um papel crucial no abastecimento de contingentes populacionais concentrados por meio de adutoras e serviços de tratamento e distribuição de água, em geral urbanos e periurbanos, não beneficiando a demanda difusa rural.
} 
e agroecologia pudessem traduzir a mesma ideia, com o tempo os grupos interessados passaram a reconhecer que a "convivência com o semiárido", descrita anteriormente, era a melhor tradução para a "agroecologia" na região.

A agroecologia está fortemente baseada na eficiência da utilização do capital natural e nas relações tróficas entre agroecossistemas locais (Ogilvy, 2015). Isto repercute tanto na racionalidade da sua conversão em outros ativos como na possibilidade de renovação e manutenção. No caso das condições ambientais do semiárido, cresce em importância a noção da composição de estoques capazes de suportar de forma mais sustentável os períodos de estiagem prolongada.

\subsection{O campesinato e o semiárido}

Parte da solução para a convivência com o semiárido reside na relação entre os agricultores e a natureza, em especial a agricultura familiar camponesa, que lhe está mais próxima. Essa relação é facilitada pelas características da agricultura camponesa e sua divisão do trabalho em um tipo particular de equilíbrio interno (Chayanov, 1966). A agricultura familiar camponesa ganhou centralidade na ação da sociedade civil pela reivindicação de políticas públicas a partir dos anos 1990. Levaram-se anos até que as políticas pudessem ser alteradas e as ideias ganhassem a expressão de políticas de massa. Mesmo assim, haveria que se demonstrar a eficácia de seus efeitos em um novo período longo de seca. As propostas e alternativas foram lenta e progressivamente desenvolvidas por meio da capacidade de inovação de famílias camponesas na região. Elas tendem a compartilhar vários serviços e informações, criando um sistema ecológico-social com grande efeito na capacidade de resiliência (Baumgärtner et al., 2010). O conjunto de alternativas desenvolvidas e experimentadas no âmbito da agricultura familiar criou um ordenamento em bases ambientais típicas de um sistema econômico não capitalista, potencializando a ocupação do espaço agrário e tornando a atividade agrícola mais eficaz e sustentável.

\subsection{Outros fatores que levam à segurança em tempos de seca}

Além dos elementos acima descritos, outros fatores também atuam para construir um ambiente de segurança em tempos de seca:

\section{- A diversificação de atividades econômicas}

- Quanto mais amplas e diversas forem as atividades e os sistemas dominados e geridos pela família, maior será a resiliência em tempos de crise, como os períodos de seca;

- Acesso a programas de seguridade social - Garantem renda adicional que, na unidade camponesa, é não raro destinada a revitalizar os próprios sistemas de convivência com o semiárido;

- Formação de novos estoques - A imprevisibilidade climática exige investimentos permanentes em estruturas e processos de constituição de estoques para resistir ao longo e cada vez mais incerto período de seca;

- Interatividade comunitária e relações sociais de proximidade - Potencializam a economia de mão de obra, oferecem canal de informação e possibilitam a troca de experiências exitosas e sinergias para a busca de soluções tanto coletivas como individuais; 
- $\quad$ Equidade de gênero - As mulheres estão responsáveis por praticamente todos os sistemas relacionados à segurança alimentar. Neste sentido, quanto mais equilibradas forem as relações de trabalho entre os membros da família, com destaque para a supressão da divisão sexual do trabalho, melhores serão a produtividade e a eficiência na luta pela segurança. Além disso, menor será o esforço para o enfrentamento das condições adversas. Por outro lado, a emancipação das mulheres pode representar importantes ingressos para a economia doméstica (Siliprandi \& Cintrão, 2011), tanto pela via das políticas e programas de seguridade como pelo potencial de desenvolvimento de atividades não agrícolas por mais membros da família.

- $\quad$ Agregação de valor e mercado - Agregar valor aos produtos oriundos da propriedade representa uma valorização do trabalho e do esforço dos membros da família, com aumento da produtividade do trabalho e otimização da gestão dos sistemas em tempos de crises provocadas pelas secas.

\section{Resultados sobre as políticas públicas}

A sociedade civil organizada teve papel decisivo nas mudanças observadas. Esta centralidade contou com o contexto favorável para implementação de mudanças nos referenciais da política pública. Devem ser levados em consideração a emergência do debate acerca do desenvolvimento sustentável, o fortalecimento da noção de territórios rurais para implantação de políticas, a valorização da multifuncionalidade da agricultura familiar e a reivindicação de políticas para a sua estabilidade social e econômica.

O fortalecimento da organização social melhorou as condições de governança das políticas públicas, influindo sobre o resultado das políticas de apoio à convivência com o semiárido, como as implementadas pela Articulação Semiárido Brasileiro $\left(\mathrm{ASA}^{4}\right)$ e nos bons resultados obtidos por novos modelos de assessoria técnica permanente voltados para a região semiárida com enfoque territorial, a exemplo do Projeto Dom Hélder Câmara, PDHC 5 (Sidersky et al., 2010).

As reflexões acerca do desenvolvimento sustentável e participativo motivaram a constituição de redes de organizações da sociedade civil, atraindo instituições governamentais e de pesquisa que partilham bons resultados e lições aprendidas, contribuindo para a mitigação dos impactos da seca de 2013, quando comparada a suas predecessoras, em especial à de 1993.

É certo que a valorização da agricultura familiar no âmbito da formulação de políticas públicas para o meio rural brasileiro não foi algo

\footnotetext{
${ }^{4}$ A Articulação no Semiárido Brasileiro (ASA) é uma rede de entidades da sociedade civil, organizada por Estados que têm porções de seus territórios no semiárido (MG, BA, SE, AL, PE, PB, RN, CE, PI e MA). Reúne mais de três mil entidades com naturezas diversas - sindicatos rurais, associações de agricultores e agricultoras, cooperativas, ONGs, OSCIPs, etc. (www.asabrasil.org.br)

5 O Projeto Dom Hélder Câmara foi uma iniciativa inovadora para o Nordeste Semiárido Brasileiro, fruto de um acordo de empréstimo entre o Governo Federal e o Fundo Internacional para o Desenvolvimento da Agricultura iniciado em 2000. Chegou a beneficiar 15 mil famílias (346 associações/77 municípios), priorizando o território como vetor de desenvolvimento e a agroecologia e a convivência com o semiárido como fundamentos para a ação de assistência técnica junto à agricultura familiar da região (Sidersky et al., 2010).
} 
específico para a região semiárida, mas talvez tenha sido sobre a região semiárida que esta inversão de prioridades tenha causado mais impacto. Aproximadamente $50 \%$ de todos os estabelecimentos da agricultura familiar do Brasil se situa na região Nordeste, correspondendo a $35 \%$ da área cultivada por este público (EMBRAPA, 2014). Sua presença na região semiárida, além de expressiva, associa-se à extrema pobreza, fazendo com que seus resultados e impactos fossem proporcionalmente mais intensos.

Programas como $\mathrm{P} 1 \mathrm{MC}$ e $\mathrm{P} 1+2^{6}$, geridos pela ASA, para estoques em segurança hídrica e promoção da agroecologia, além de incentivos proporcionados por programas como o $\mathrm{PAA}^{6} \mathrm{e} \mathrm{o}$ $\mathrm{PNAE}^{8}$, são indicadores visíveis deste processo. Além disso, as políticas sociais de transferência de renda e aposentadoria rural substituíram as políticas emergenciais de distribuição de cestas básicas e frentes de emergência, o que tornou um pouco mais duradouras as ações de seguridade social.

Essas políticas se incorporaram ao cotidiano das famílias rurais, que contam com estes ingressos na construção de suas estratégias de segurança alimentar. Este tipo de política, ainda que assistencial, gera mais autonomia para as famílias do que antigas políticas emergenciais de distribuição de cestas básicas e alistamento de trabalhadores em frentes de serviço. Mesmo ao Bolsa Família não se pode atribuir um caráter "assistencialista", uma vez que transferem-se recursos condicionando-os a uma contrapartida importante das famílias para fazer jus a eles. E, o mais importante, essa transferência é realizada de forma impessoal e desatrelada de compromissos e obrigações com grupos políticos. Com os recursos, transfere-se também a autonomia para decidir como utilizá-los.

Tal fato não acontece na Operação Carro-Pipa do Ministério da Integração, executado em parceria com o Exército, e nas suas versões estaduais, geralmente em parceria com os órgãos estaduais de assistência técnica. Nestes casos, não são recursos para aquisição de água por carros-pipa que são transferidos para as famílias, mas sim a própria água que é distribuída. Não há nenhuma contrapartida das famílias para receber a água e a coordenação da distribuição passa por frágeis comissões municipais, que permitem o controle e a tutela por lideranças políticas. A Operação Carro-Pipa, portanto, repete os procedimentos que no passado alimentaram a indústria da seca.

Um outro grupo de políticas se refere à transferência de renda e de seguridade. Nos últimos anos, foram criados e ampliados programas e políticas governamentais que tiveram repercussão direta na composição da renda das famílias e proporcionaram melhores indicadores de segurança alimentar e nutricional da população rural. Com eles mudou a percepção da população rural acerca de suas garantias: a população percebia a severidade da seca, mas se sentia assegurada pelo conjunto de investimentos realizados e pelas políticas públicas.

Os principais aportes financeiros oriundos de programas de seguridade social e segurança hídrica na região semiárida são descritos a seguir:

\footnotetext{
${ }^{6}$ Programa Um Milhão de Cisternas, voltado para abastecimento humano, e Programa Uma Terra e Duas Águas, para dotar as propriedades de reservatório de água para a produção e outros usos.

7 Programa de Aquisição de Alimentos.

${ }^{8}$ Programa Nacional da Alimentação Escolar.
} 
Bolsa Família - Praticamente todas as famílias residentes na zona rural do semiárido tiveram acesso ao programa $(100 \%$ dos entrevistados em campo) entre os anos de 2010 e 2016. O fato de os recursos serem geridos prioritariamente pelas mulheres fez com que eles fossem otimizados na unidade familiar para atender a uma estratégia de segurança. Além do empoderamento da mulher no âmbito doméstico, os benefícios à família como um todo, especialmente a segurança alimentar, eram evidentes.

Aposentadoria Rural - Trata-se da aposentadoria por idade destinada a trabalhadores e trabalhadoras em áreas rurais ou pescadores e pescadoras artesanais que exerceram as atividades diariamente, individualmente ou com o auxílio da família. Regulada pelo regime geral da previdência da época, tinha como base o salário mínimo, direito adquirido com a Constituição de 1988, nivelando os valores dos benefícios rurais e urbanos. Antes disso, o maior benefício na área rural era de meio salário mínimo. Com esta equiparação, as aposentadorias rurais se beneficiaram das iniciativas do governo federal de estabelecer uma política de recuperação do poder de compra do salário mínimo. Uma vez que o salário mínimo nacional saiu de um patamar abaixo dos cem dólares para mais de duzentos dólares, seu poder de compra sai de 1,02 cesta básica em 1993 para em 2009 ultrapassar as duas cestas básicas, mantendo-se assim até 2016 (DIEESE, 2016).

Salário Maternidade - Benefício pago às mulheres trabalhadoras rurais ou agricultoras familiares, correspondentes à categoria previdenciária de "segurada especial", que se tornavam mães tanto por parto quanto por adoção (Governo Federal, 2016c). Mesmo sendo um benefício transitório, tornou-se estratégico para a economia doméstica, haja vista que a maior parte do trabalho produtivo da unidade familiar é realizado pelas mulheres. Além disso, a dupla jornada de trabalho que recai sobre elas tem um peso ainda maior durante o período pós-parto. As mulheres beneficiadas conseguiram mais autonomia financeira para cuidar da saúde e da alimentação. O salário maternidade e o direito de acesso direto à aposentadoria rural pelas mulheres foram destacados pela Organização Internacional do Trabalho (OIT) como políticas estratégicas para a redução da pobreza e para o crescimento econômico nas zonas rurais.

Bolsa Estiagem - Auxílio disponibilizado entre 2012 e 2014 para o enfrentamento da seca. A responsabilidade da sua distribuição ficou a cargo do Ministério da Integração Nacional. Era destinado aos municípios que não aderiram ao Garantia Safra (Governo Federal, 2015), nas áreas atingidas pela seca, e para famílias com renda mensal inferior ao salário mínimo. $\mathrm{O}$ valor mensal da bolsa era de $\mathrm{R} \$ 80$ até o fim do programa, em 2014. Ainda que tivesse um caráter temporário, cumpriu um papel importante no rompimento das antigas relações clientelistas que se estabeleciam nos programas de emergência quando se transformavam os direitos da população atingida em moeda de troca para se acumular capital político.

Garantia Safra - O Programa Garantia Safra é uma ação voltada para os agricultores familiares localizados na região semiárida que sofreram perda de safra por motivo de seca ou excesso de chuvas. É uma política vinculada ao Programa Nacional de Fortalecimento da Agricultura Familiar-PRONAF (Governo Federal, 2016a) e exige contrapartida dos estados e municípios. Criado em 2002 pelo Governo Federal, garantiu condições mínimas de sobrevivência aos agricultores familiares de muni- 
cípios sistematicamente sujeitos à perda de safra por estiagem ou excesso hídrico. Em 2016, o valor pago do benefício Garantia Safra foi de R \$ 850,00 (oitocentos e cinquenta reais) por família, com pagamentos realizados em cinco parcelas mensais.

Operação Carro-Pipa - Programa de distribuição de água por carros-pipa gerenciado pelo Ministério da Integração em parceria com o Exército. $\mathrm{O}$ programa foi recriado e vem operando desde 2010. Os dados oficiais afirmam que em 2016 havia quase 6.800 carros-pipa em toda a região semiárida a serviço do programa federal (Governo Federal, 2016b). Possuir uma cisterna era condição básica para ser beneficiário do programa. Mas a ordem e a escala de entrega de água são definidas conjuntamente entre o Exército e as autoridades locais. Para estar inscrito no programa, os municípios tinham que protocolar uma demanda diretamente na Secretaria Nacional de Defesa Civil do Ministério da Integração; a demanda era encaminhada ao Exército, que fazia uma avaliação técnica da realidade local.

Diferentemente dos auxílios e benefícios anteriores, em que se creditam recursos em dinheiro por meio de cartão pessoal e intransferível, neste caso o benefício era a água, distribuída de casa em casa. Sua distribuição depende das decisões tomadas por alguém que coordena as atividades localmente, cujos critérios podem estar sujeitos a ingerências políticas locais.

Como não havia custos para o beneficiário, a tendência era se consumir a água para diferentes finalidades, muito além daqueles tipos de consumo que as águas da cisterna teriam, caso sua origem fosse a chuva.

O princípio pelo qual se consideram as cisternas vetores de cidadania refere-se ao fato de que a captação de água da chuva torna as famílias menos dependentes de favores políticos em momentos de seca. Com o aprofundamento da seca iniciada a partir de 2011, a reativação das políticas de distribuição de água em carros-pipa, ao invés de servir como sistema complementar à água da chuva, passou pouco a pouco a ser a regra e não a exceção, e seu ressurgimento tem novamente fins políticos, em que era exigida dos beneficiários alguma contrapartida em troca da água. Essa contrapartida poderia ser o voto em certos políticos ou compromissos eleitorais. Até a escolha dos pipeiros que operam o sistema obedecia a critérios políticos e mesmo a água é comprada em "donos" de fontes por indicação política.

Crediamigo - Programa de crédito gerido pelo Banco do Nordeste para estimular o microempreendedorismo (microempreendedor individual, empresário individual, autônomo ou sociedade empresária). Não é um crédito exclusivo para o semiárido, mas tem repercussão sobre a economia da região, na medida em que atende os setores informais ou formais da economia. Alguns aspectos que simbolizavam as facilidades eram a burocracia facilitada, o atendimento feito no próprio local do empreendimento, a liberação rápida do empréstimo de uma só vez e os empréstimos renováveis (BNB, 2017). A pesquisa de campo comprovou a tomada do empréstimo ao menos em dois casos, cujos tomadores desenvolviam atividades não agrícolas que repercutiam sobre a renda da família e, portanto, sobre a convivência com o semiárido.

\section{Dinâmica de uma propriedade rural do semiárido em três momentos}

As situações enfrentadas pela agricultura familiar na obtenção de seu sustento e na segurança 
alimentar têm mudado significativamente, com impactos positivos sobre a qualidade de vida da população local. A Figura 11 mostra a linha do tempo construída pelos moradores locais, um dos resultados do diagnóstico na Comunidade de Tamboril, em Campo Alegre de Lourdes/BA. Nela fica clara a mudança nas ações que levaram à redução da mortalidade infantil, um dos indicadores desta nova realidade.

As diferentes políticas e ações operam em um sistema integrado e sinérgico, cuja distinção em relação ao impacto causado é difícil. Para melhorar a compreensão destas interações, elas serão descritas resumidamente nos itens a seguir, considerando três situações: (i) ano normal, antes das intervenções; (ii) ano seco, antes das intervenções; e (iii) após as intervenções e seus impactos sobre a seguridade social.

\subsection{Situação 1: ano "normal”, antes das intervenções}

Em uma situação convencional, considerando-se a agricultura de subsistência, as famílias fundamentalmente dependem da interação entre os fatores naturais e seus meios de produção (Figura 12). As entradas ecológicas 1 tornam-se a base do sistema, alimentando um complexo de sistemas produtivos que, para efeito de representação gráfica, foram simplificados em quatro subsistemas: roçados, quintais, áreas de reserva e criação animal.

Estes subsistemas interagem com diversos sistemas de estocagem. As entradas alimentam diretamente as estruturas de estocagem, principalmente água da chuva em reservatórios e captação de água subterrânea em poços. Os sistemas produtivos recebem estes aportes diretamente ou por meio dos estoques. Por sua vez, eles alimentam as estruturas de estoque de alimentos que servirão de base para o sustento da família 2 ou poderão ser destinados ao mercado 3. Os estoques servem para estabilizar a produção, aumentando a sua resistência principalmente às estiagens, e, eventualmente, enchentes. A unidade familiar de produção, tendo como elemento central o núcleo familiar, mantém com seu entorno relações que permitem novos ingressos econômicos, seja pela venda de produtos, seja pela atuação de parte de seus membros em atividades não agrícolas 4 que ajudam a retroalimentar os ingressos econômicos 4.1 .

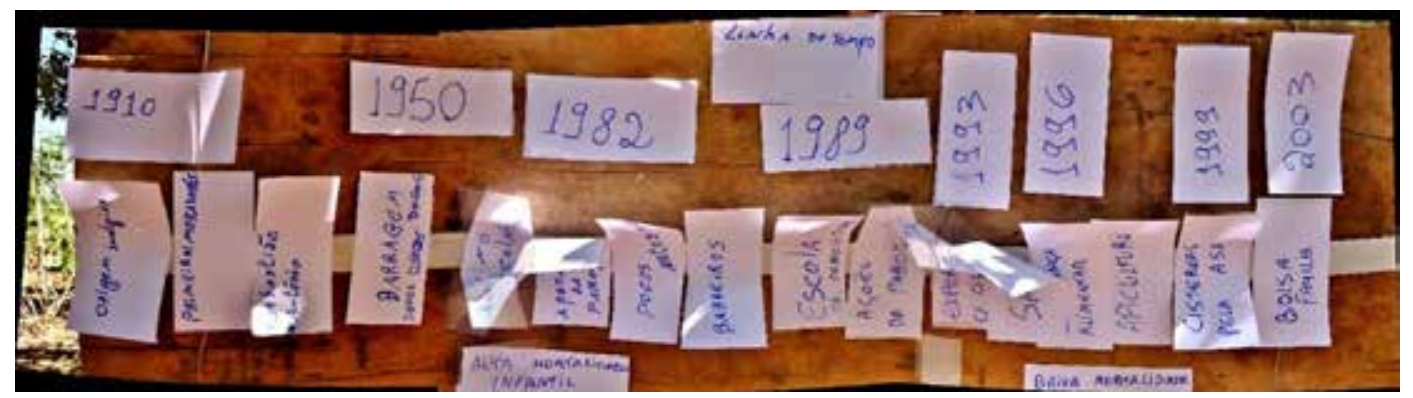

FIGURA 11 - Linha do tempo da comunidade de Tamboril, em Campo Alegre de Lourdes/BA, indicando mudanças ocorridas desde 1993 que têm levado a redução da mortalidade infantil (SASOP, 2015). 


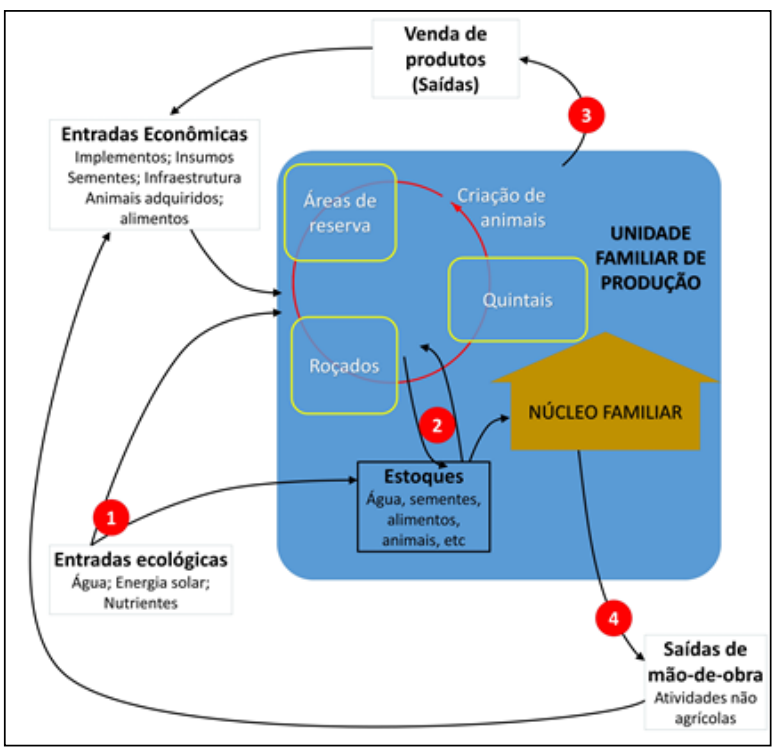

FIGURA 12 - Funcionamento da Unidade de Produção Familiar - Situação Normal.

\subsection{Situação 2: ano seco, antes das intervenções}

A crise gerada por uma estiagem prolongada se inicia com a quebra de safra nos sistemas de roçado 5, em geral produzido em sequeiro e, portanto, mais dependente das chuvas (Figura 13).

Há também uma redução dos aportes aos sistemas de estocagem de água 6. Sem reposição, e com a redução dos aportes de água aos sistemas produtivos, os estoques de água se exaurem mais rapidamente 7 . Isto se dá pelo aumento da demanda para irrigação de salvação e pelo consumo das reservas de grãos como alimento humano ou animal, ameaçando os estoques de sementes.

Com o aprofundamento da estiagem, o núcleo familiar passa a estar ameaçado pela saída de pessoas em busca de oportunidades de trabalho e renda 8 .
Com a migração, o risco de rompimento do tecido social é maior 8a. Assim, os ingressos oriundos de atividades não agrícolas reduzem a sua participação na reestruturação dos sistemas produtivos 9 , fragilizando a resiliência dos sistemas. Desta forma, é o próprio estoque que se transforma em produto de venda para compensar as perdas de colheita $\mathbf{1 0}$, fator que aumenta ainda mais a pressão sobre os estoques e fragiliza o potencial de recuperação dos sistemas após a crise (resiliência). As circunstâncias apresentadas aqui para a situação 2 não transcorrem sem o envolvimento de políticas públicas.

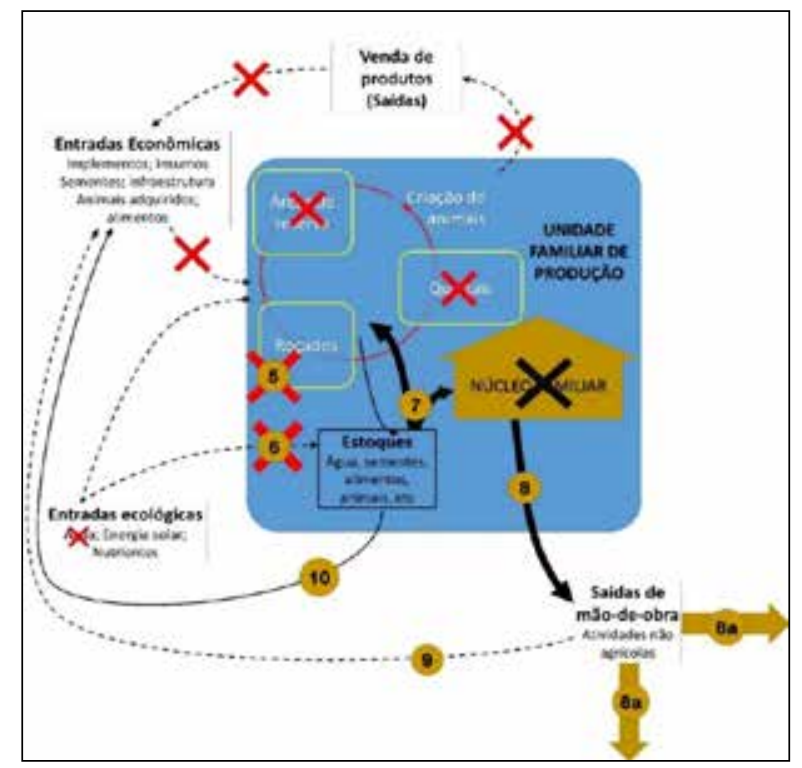

FIGURA 13 - Funcionamento da Unidade de Produção Familiar Sob impactos da seca.

Contudo, os resultados de políticas ineficazes se assemelham às suas próprias inexistências. Além disso, políticas de formação de estoques em grandes obras criam um atrativo para a saída ainda mais intensa de mão de obra da região $\mathbf{8 a}$, além de tornar a população mais dependente de ações 
clientelistas, seja a oferta temporária de trabalho, seja a distribuição de alimentos para o combate à fome e à desnutrição.

A eficácia da política depende da forma como os atores locais são apoiados pelos instrumentos de intervenção adotados. Os investimentos realizados a partir dos anos 1990 para conhecer a complexidade das unidades familiares de produção no semiárido permitiram a concepção de políticas de seguridade mais eficazes e transformadoras.

\subsection{Situação 3: após as intervenções e seus impactos sobre a seguridade social}

A existência das políticas mencionadas anteriormente pode aparentemente lembrar as ações emergenciais tradicionais de corte assistencialista, pontuais e clientelistas. As percepções colhidas em campo mostram que, mesmo tendo origem fragmentada em distintos órgãos, estas políticas atuaram de forma sinérgica na organização da economia camponesa. Por isso, reforçam os sistemas produtivos no que diz respeito a sua resistência a uma crise hídrica crescente e recrudescente.

Analisando-se a Figura 14 de baixo para cima, temos inicialmente investimentos na composição e na estrutura dos estoques 11. Com a ampliação geral da captação de água de chuva, aliada à descentralização dos reservatórios, tornando-os mais próximos das casas, criaram-se novas possibilidades para melhor aproveitamento da água e, consequentemente, de convivência com o semiárido. Este conceito, fundado em princípios agroecológicos, se inicia com o reforço dos estoques para resistir às estiagens e reabilitar os sistemas produtivos após seu fim (resiliência). Além da água, é fundamental reforçar os estoques de sementes e forragem para os sistemas de criação animal. A formação de estoques deve estar em consonância com a proteção da agrobiodiversidade e, portanto, da manutenção de padrões genéticos de plantas e animais adaptados às condições do semiárido.

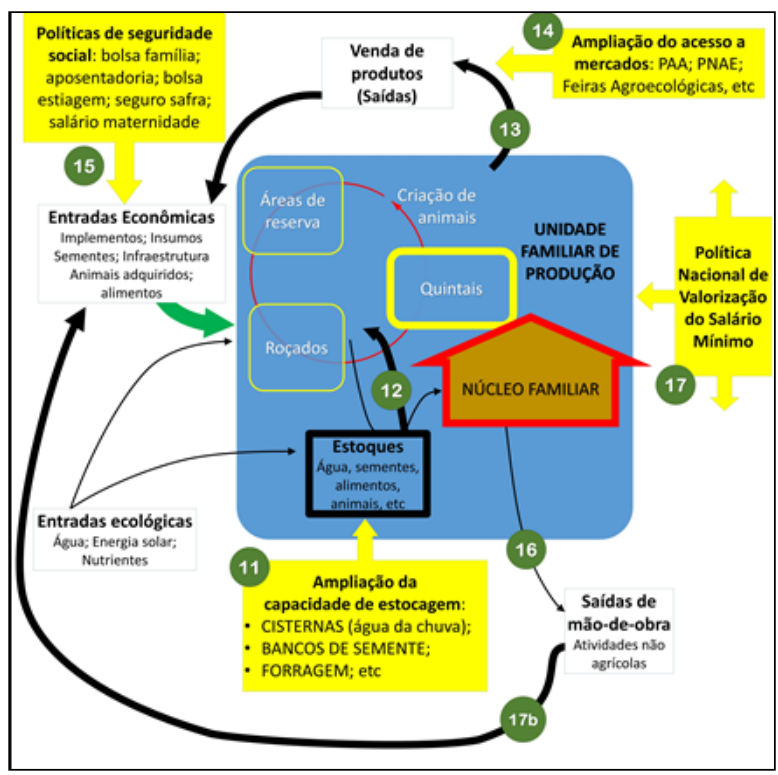

FIGURA 14 - Funcionamento da Unidade de Produção Familiar - Sob impacto das políticas públicas de segurança alimentar e convivência com o semiárido.

Dessa forma, em condições de crises provocadas pela seca, os estoques têm mais capacidade de suportar a pressão da demanda 12 e manter em funcionamento, por mais tempo, os sistemas produtivos que dão suporte à demanda doméstica. Os sistemas de quintais são particularmente reforçados com a ampliação dos estoques de água. Com a manutenção das atividades nos quintais, há continuidade na destinação de produtos ao mercado 13 e, com isso, a manutenção de ingressos econômicos para a família. Além disso, os sistemas de quintais 
estão fortemente relacionados à segurança alimentar da família.

Esse processo se alia a um segundo campo de políticas públicas, voltadas para o acesso a mercados locais de feiras agroecológicas e mercados institucionais com auxílio dos programas PAA e PNAE14. Desta forma, cria-se a primeira sinergia entre políticas públicas, aliando-se o reforço da estocagem à ampliação do acesso aos mercados.

A indústria da seca promoveu durante anos um processo profundo de descapitalização da família camponesa, que vivia em extrema pobreza. As necessidades atuais da população derivam desse processo histórico de exclusão associado à estrutura fundiária e aos ciclos de dependência. Esse quadro motivou a criação de diversos programas de seguridade social, que tiveram como efeito a quebra do ciclo vicioso de produção e reprodução da pobreza15. Os resultados observados em campo apontam que as políticas implementadas até meados da década passada permitiram entradas econômicas importantes para a família, tendo sido inclusive utilizadas como investimentos alternativos de reforço à recomposição dos estoques e sistemas produtivos.

Por fim, é preciso levar em consideração a persistência e a relevância das atividades não agrícolas na vida familiar. Neste sentido, a busca por novas oportunidades de trabalho fora da unidade de produção segue sendo uma realidade. É preciso levar em conta dois aspectos. O primeiro é a dinamização econômica local e regional gerada pelas políticas anteriormente citadas. Ela permite o surgimento de oportunidades de trabalho mais próximas da unidade de produção, reduzindo o impacto da migração para outras regiões 16 . O segundo é a política nacional de valorização do salário mínimo 17, que fez com que tanto as oportunidades de trabalho quanto as políticas de seguridade atreladas ao salário mínimo ajudassem a compor melhor a renda das famílias, trazendo mais ingressos econômicos $\mathbf{1 7 b}$. Desta forma, há um claro efeito na estabilidade do núcleo familiar, com aumento dos benefícios pela permanência na região, o que fez aumentar o custo de oportunidade da emigração.

\section{Considerações finais}

O paradigma da solução hidráulica foi substituído por uma política diversificada de ação que, por um lado, é tecnicamente descentralizada, distributiva e multifatorial, e, por outro, se orienta para a população local, considerando as características da base social dominantemente camponesa.

A descentralização da oferta de água, a formação de estoques e a adoção de tecnologias de baixo custo representaram elementos centrais para a sustentabilidade do desenvolvimento rural em bases agroecológicas. Estas inovações consolidaram o conceito de convivência com o semiárido, tornando mais eficiente o enfrentamento das estiagens prolongadas.

A longa trajetória da sociedade civil na região permitiu afirmar o seu papel crucial para o desenvolvimento das políticas públicas. As ideias foram desenvolvidas e testadas localmente e difundidas e adaptadas em redes sociotécnicas, que contaram ainda com grandes mobilizações reivindicatórias. Tais políticas têm incorporado gradativamente os conceitos de convivência com o semiárido em bases sustentáveis.

No entanto, ao observar-se em campo o funcionamento de programas como a Operação Carro-Pipa, é possível perceber a persistência residual da 
solução hidráulica na esfera pública da ação para o desenvolvimento.

Além disso, os elementos colhidos em campo não permitiram esgotar suficientemente os limites de resistência dos sistemas para convivência com o semiárido em condições climáticas ainda mais intensas do que as verificadas na seca de 2012-16, ainda que esta tenha sido provavelmente a seca mais severa da história. Entretanto, com o aprofundamento das mudanças climáticas, abre-se uma janela a mais de incertezas.

Por fim, a abordagem acerca das interatividades entre os diferentes investimentos e políticas públicas permitiu levantar elementos preliminares sobre as externalidades ambientais e sociais positivas das novas abordagens para a convivência com o semiárido. No entanto, há também efeito visível de fatores externos na estabilidade dos sistemas da agricultura familiar,

\section{Referências}

Aragão, J. O. A general circulation model investigation of the response to El Niño. Colorado: s.n., 1986.

Baumgärtner, J.; Tikubet, G.; Gilioli, G. Towards Adaptive Governance of Common-Pool Mountainous Agropastoral Systems. Sustainability, 2, 1448-1471. 2010.

BNB. Crediamigo. 2017. Disponível em: <https://www.bnb. gov.br/crediamigo>. Acesso em: jun. 2017.

Buainain, A. M.; Garcia, J. R. Desenvolvimento rural do semiárido brasileiro: transformações recentes, desafios e perspectivas. Confins on-line - Revista Franco-Brasileira de Geografia, 19, 26, nov. 2013.

Buriti, C. de O.; Aguiar, J. O. Secas, migrações e representações do Semiárido na literatura regional: por uma história ambiental dos dos Sertões do Nordeste Brasileiro. Textos \& Debates - Revista de Ciências Humanas da Universidade Federal de Roraima, 1(15), 7-31, 2008. proporcionados sobretudo pela recuperação do valor do salário mínimo, da dinamização econômica como um todo e dos programas de transferência de renda. Esses últimos foram de fato parcialmente influenciados pela abordagem crítica da sociedade civil aos programas emergenciais do passado.

Não é possível afirmar que as ações e políticas de convivência com o semiárido de base agroecológica foram assimiladas pelo campesinato do semiárido de forma linear e na mesma intensidade. Mas o campesinato sertanejo hoje dispõe de alternativas para a intensificação agroecológica dos seus sistemas de produção, em contraposição aos modelos de intensificação convencionais. O sucesso desse conjunto de alternativas e políticas no enfrentamento da maior seca que se tem notícia (2012-16) permite às famílias escolher a melhor opção. A migração passa a ser feita por opção, não mais pela falta dela.

Campello Netto, M. S. C. Sobre a ação pública e as secas no Nordeste. In: Molle, F. Marcos históricos e reflexões sobre a açudagem e seu aproveitamento. Recife: SUDENE/ ORSTOM, 1994. p. 190.

Castro, J. Geografia da fome. 10. ed. Rio de Janeiro: Edições Antares, 1984.

Chayanov, A. On the Theory of Non-Capitalist Economic Systems. In: Chayanov, A. The Theory of Peasant Economy. Homewood, Illinois: The American Economic Association, 1966. p. 1-28.

CPTEC/INPE. Monitoramento Climático - Dados acumulados de precipitação pluviométrica. 2016a. Disponível em: <http://www.cptec.inpe.br/>. Acesso em: dez. 2016.

CPTEC/INPE. Índice de Precipitação Padronizado (SPI). 2016b. Disponível em: <http://climal.cptec.inpe.br/spi/pt>. Acesso em: jul. 2016. 
Di Sabbato, A.; Melo, H. P.; Lombardi, M. R.; Faria, N.; Butto, A. Estatisticas rurais e a economia feminista: um olhar sobre o trabalho das mulheres. Brasília: NEAD/MDA. 2009.

DIEESE. Nota Técnica $n^{\circ} 153$ - Politica de Valorização do Salário Mínimo: valor para 2016 é fixado em R\$ 880,00. São Paulo: s.n., 2016.

Durkheim, E. As regras do método sociológico. 3. ed. São Paulo: Martins Fontes, 2007. p. 1-14:165.

EMBRAPA - Empresa Brasileira de Pesquisa Agropecuária. AIAF 14 - Agricultura Familiar no Brasil. 2014. Disponível em: $<$ https://www.embrapa.br/aiaf-14-agricultura-familiar-no-brasil>. Acesso em: jun. 2017.

Ferreira, A. P. L. La importância de la perspectiva feminista en el empoderamiento de las mujeres campesinas. Cordoba: s.n., 2008.

Governo Federal. Auxílio Emergencial Financeiro. Disponível em: <http://mds.gov.br/assuntos/cadastro-unico/o-que-e-e-para-que-serve/auxilio-emergencial-financeiro>. Acesso em: nov. 2015.

Governo Federal. Garantia-Safra. Disponível em: $<$ http:// www.mda.gov.br/sitemda/secretaria/saf-garantia/sobre-o-programa>. Acesso em: dez. 2016a.

Governo Federal. Ministério da Integração Regional. Disponível em: <https://www.brasil.gov.br/imagens-banners-em-geral/carro-pipa.png/view>. Acesso em: nov. 2016 b.

Governo Federal. Valor do salário maternidade. Disponível em: <http://www.previdencia.gov.br/servicos-ao-cidadao/ todos-os-servicos/salario-maternidade/valor-salario-maternidade/>. Acesso em: nov. 2016c.

Granovetter, M. S. The Strength of Weak Ties. American Journal of Sociology, 78(6), 1360-1380, May 1973.

Harzallah, A.; Rocha de Aragão, J. O.; Sadourny, R. Interannual rainfall variability in northeast Brazil: Observation and model simulation. International Journal of Climatology, 16, 861-878, 1996.

IBGE - Instituto Brasileiro de Geografia e Estatística. Semiárido Brasileiro. 2018. Disponível em: https://www. ibge.gov.br/geociencias/cartas-e-mapas/mapas-regionais/ 15974-semiarido-brasileiro.html? $=\& \mathrm{t}=$ downloads. Acesso em: 30 abr. 2020.
Leite, J. C. F.; Souza, K. L. de. O novo perfil do Nordeste Brasileiro no Censo Demográfico 2010. Fortaleza: s.n., 2012.

Mattos, L. C. Um tempo entre secas: superação de calamidades sociais provocadas pela seca através das ações em defesa da convivência com o semiárido. Rio de Janeiro, Tese (Doutorado em Ciências Sociais, Desenvolvimento, Agricultura e Sociedade) - UFRRJ, 2017.

Mattos, L.C.; Trier, R. Diagnóstico rápido e participativo dos recursos hídricos em São Felipe, Tauá/CE. Recife: s.n., 1994.

McKee, T. B.; Doesken, N. J.; Kleist, J. The relationship of drought frequency and duration to time scales. Anaheim, California, s.n., 1993. p. 17-22.

Medeiros, S. de S.; Cavalcante, A. M. B.; Perez Marin, A. M.; Tinoco, L. B. M.; Hernan Salcedo, I.; Pinto, T. F. Sinopse do Censo Demográfico para o Semiárido Brasileiro. Campina Grande: s.n., 2012.

Nimer, E. Climatologia do Brasil. 2. ed. Rio de Janeiro: IBGE, DRNEA, 1989.

Ogilvy, S. Developing the ecological balance sheet for agricultural sustainability. Sustainability Accounting, Management and Policy Journal, 6(2), 110-137, 2015.

Olivi, J. B. Viúvas da seca. Brasil: Rede Globo de Televisão, 1983.

SASOP. Sistematização do Diagnóstico Rural Participativo - DRP - Comunidade Tamboril. Campo Alegre de Lourdes: s.n., 2015.

SDR/MI/Brasil. Nova delimitação do Semiárido Brasileiro. Brasília: s.n., 2005.

Sidersky, P.; Jalfim, F.; Araújo, E. A estratégia de Assessoria Técnica Permanente do Projeto Dom Hélder Câmara. 2. ed. Recife: PDHC, 2010.

Siliprandi, E.; Cintrão, R. As mulheres agricultoras e sua participação no Programa de Aquisição de Alimentos (PAA). In: Butto, A.; Dantas, I. Autonomia e cidadania: política de organização produtiva para as mulheres no meio rural. 1. ed. Brasília: MDA, 2011.

Villa, M. A. Vida e morte no sertão: história das secas no Nordeste nos séculos XIX e XX. 1. ed. São Paulo: Ática/ Instituto Teotônio Vilela, 2000. 